\title{
Developmental and Environmental Regulation of Cuticular Wax Biosynthesis in Fleshy Fruits
}

\author{
Priyanka Trivedi', Nga Nguyen ${ }^{1}$, Anne Linn Hykkerud ${ }^{2}$, Hely Häggman', \\ Inger Martinussen ${ }^{2}$, Laura Jaakola ${ }^{2,3 *}$ and Katja Karppinen ${ }^{1,3}$ \\ ${ }^{1}$ Department of Ecology and Genetics, University of Oulu, Oulu, Finland, ${ }^{2}$ Norwegian Institute of Bioeconomy Research, \\ Ås, Norway, ${ }^{3}$ Climate Laboratory Holt, Department of Arctic and Marine Biology, UiT the Arctic University of Norway, \\ Tromsø, Norway
}

OPEN ACCESS

Edited by:

Antonio Ferrante,

University of Milan, Italy

Reviewed by:

Sergio Angeli,

Free University of Bozen - Bolzano,

Italy

José Alejandro Heredia-Guerrero, Istituto Italiano di Tecnologia, Italy

*Correspondence: Laura Jaakola

laura.jaakola@uit.no

Specialty section:

This article was submitted to

Crop and Product Physiology, a section of the journal

Frontiers in Plant Science

Received: 11 December 2018

Accepted: 21 March 2019

Published: 11 April 2019

Citation:

Trivedi P, Nguyen N, Hykkerud AL, Häggman H, Martinussen I, Jaakola L

and Karppinen K (2019)

Developmental and Environmental Regulation of Cuticular Wax

Biosynthesis in Fleshy Fruits.

Front. Plant Sci. 10:431.

doi: 10.3389/fp/s.2019.00431
The aerial parts of land plants are covered by a hydrophobic layer called cuticle that limits non-stomatal water loss and provides protection against external biotic and abiotic stresses. The cuticle is composed of polymer cutin and wax comprising a mixture of very-long-chain fatty acids and their derivatives, while also bioactive secondary metabolites such as triterpenoids are present. Fleshy fruits are also covered by the cuticle, which has an important protective role during the fruit development and ripening. Research related to the biosynthesis and composition of cuticles on vegetative plant parts has largely promoted the research on cuticular waxes in fruits. The chemical composition of the cuticular wax varies greatly between fruit species and is modified by developmental and environmental cues affecting the protective properties of the wax. This review focuses on the current knowledge of the cuticular wax biosynthesis during fleshy fruits development, and on the effect of environmental factors in regulation of the biosynthesis. Bioactive properties of fruit cuticular waxes are also briefly discussed, as well as the potential for recycling of industrial fruit residues as a valuable raw material for natural wax to be used in food, cosmetics and medicine.

Keywords: fruit, cuticle, cuticular wax, biosynthesis, regulation, temperature, light, bioactivity

\section{INTRODUCTION}

The primary surfaces of aerial parts of land plants are covered by a hydrophobic layer called cuticle. The cuticle is composed of polyester cutin and a mixture of lipidic compounds collectively called wax. The chemical composition of cuticular wax varies between species and organs but is also dependent on the developmental stage and environmental conditions (Yeats and Rose, 2013). Cuticular wax appears as amorphous "intracuticular wax" embedded in cutin matrix, that is connected to the polysaccharides on the underlying epidermal cell walls, and as "epicuticular wax" that may exist as crystallized to various micro-morphologies (Koch and Ensikat, 2008; Fernández et al., 2016; Barthlott et al., 2017; Figure 1). Cuticle not only provides protection against desiccation but also has a role in plant development and environmental interactions (Yeats and Rose, 2013). In fleshy fruits, cuticular waxes have a crucial role in minimizing water loss/uptake through an often astomatous surface, providing mechanical support, preventing fruit softening, and in resistance to pathogens (Saladié et al., 2007; Martin and Rose, 2014; Wang J. et al., 2014). The cuticle in fruits is usually thicker than in leaves and the epicuticular wax is often visible to the naked eye as a white, dull, or glossy coating. Alterations in cuticular wax biosynthesis, load and composition take place during the fruit development to keep it continuous and adjusted to its tasks. 
From a human perspective, fleshy fruits are an indispensable part of a healthy diet and cuticular wax affects important quality traits for consumers, such as fruit color, texture, shelflife, sensory and nutritional quality, and preventing fruit cracking (Lara et al., 2014; Petit et al., 2017; Chu et al., 2018a; Tafolla-Arellano et al., 2018).

Recent reviews exist concerning cuticular wax biosynthesis in vegetative organs of plants (e.g., Lee and Suh, 2013; Yeats and Rose, 2013; Borisjuk et al., 2014) but also in fruits mainly focusing on cuticle composition (Lara et al., 2015), genetic regulation of cuticle assembly (Hen-Avivi et al., 2014) and role of cuticle in postharvest quality (Lara et al., 2014). The present review compiles the current knowledge on the developmental and environmental regulation of biosynthesis and composition of cuticular waxes in fleshy fruits.

\section{CUTICULAR WAX COMPOSITION AND BIOSYNTHESIS IN FRUITS}

The major components of plant cuticular waxes are verylong-chain fatty acids (VLCFAs, typically $\mathrm{C}_{20}-\mathrm{C}_{34}$ ) and their derivatives including alkanes, aldehydes, primary and secondary alcohols, ketones, and esters along with secondary metabolites, such as triterpenoids, sterols, tocopherols, and phenolic compounds (Kunst and Samuels, 2009; Yeats and Rose, 2013). The composition of cuticular wax varies widely among fruit species and cultivars (Table 1). While alkanes are common wax components in cuticles of different plant organs, triterpenoids are present especially in fruits (Szakiel et al., 2012). Triterpenoids and $n$-alkanes are the major compounds of cuticular wax in tomato (Solanum lycopersicum), apple (Malus $\times$ domestica), Asian pear (Pyrus spp.), sweet cherry (Prunus avium), peach (Prunus persica), and pepper (Capsicum annuum) fruits. Also, among wild tomatoes, alkanes are the dominant compounds but the content of triterpenoids varies between tomato species (Yeats et al., 2012). Instead, the cuticular wax in grape (Vitis vinifera), olive (Olea europaea), persimmon (Diospyros kaki), and blueberries (Vaccinium spp.) contain high amounts of triterpenoids but only traces of alkanes (Table $\mathbf{1}$ ).

Apart from alkanes and triterpenoids, many fruits have high proportions of other components in their cuticles. A recent study indicated high levels of primary alcohols and tocopherols in the cuticular wax of some pear cultivars (Wu et al., 2017, 2018). Plum (Prunus domestica) and some apple cultivars show high proportion of secondary alcohols in fruit cuticle, while tomato cuticle contains significant amounts of polyunsaturated constituents, including alken-1-ols and alkenes (Kosma et al., 2010). Aldehydes are abundant only in cuticles of some fruits, such as cucumber (Cucumis sativus), cranberry (Vaccinium macrocarpon), and Citrus fruits. Cuticular wax of bayberry (Myrica pensylvanica) uniquely consists of glycerolipids while blueberries contain high levels of $\beta$-diketones (Table 1).

Many of the cuticle properties are affected by the composition of wax. For example, wax composition rather than cuticle thickness has been indicated to affect water transpiration rate (Riederer and Schreiber, 2001). The presence of long-chain alkanes and aldehydes has been found to increase water impermeability of fruit cuticles, while triterpenoids and sterols have opposite effects (Vogg et al., 2004; Leide et al., 2007; Parsons et al., 2012; Wang J. et al., 2014; Moggia et al., 2016). Instead, triterpenoids were shown to enhance mechanical strength of persimmon fruit cuticle by functioning as nano-fillers (Tsubaki et al., 2013). Wax composition also affects epicuticular wax micro-morphology (Koch and Ensikat, 2008). Alkanes, aldehydes and alcohols were shown to promote the formation of epicuticular wax crystals in orange (Citrus sinensis) and apples (Liu et al., 2012, 2015; Yang et al., 2017).

The knowledge of cuticular wax biosynthesis has mainly been gained from the studies in Arabidopsis leaves, but also from tomato fruit owing to its thick, astomatous, easy-to-isolate cuticle and availability of mutants (Bernard and Joubès, 2013; Lee and Suh, 2013; Hen-Avivi et al., 2014). During recent years high-throughput sequencing has facilitated the identification of candidate genes involved in the fruit cuticle formation and wax biosynthesis in addition to tomato (Mintz-Oron et al., 2008; Matas et al., 2011) in apple (Albert et al., 2013; Legay et al., 2015), mango (Mangifera indica, Tafolla-Arellano et al., 2017), sweet cherry (Alkio et al., 2012, 2014), orange (Wang et al., 2016), pear (Pyrus pyrifolia, Wang Y. et al., 2014), and bayberry (Simpson and Ohlrogge, 2016).

The cuticular wax components are biosynthesized in the epidermal cells of fruit peel. The biosynthesis of aliphatic wax constituents utilizes $\mathrm{C}_{16}$ and $\mathrm{C}_{18}$ fatty acids produced by de novo synthesis in plastids (Figure 1). These precursors are elongated to $\mathrm{C}_{20}-\mathrm{C}_{34}$ VLCFAs in endoplasmic reticulum (ER) by the fatty acid elongase (FAE) complex with $\beta$-ketoacyl-CoA synthase (KCS) as the rate-limiting enzyme of the complex (Kunst and Samuels, 2009; Yeats and Rose, 2013). Tomato lecer6 mutant has shown that KCS plays a key role in wax aliphatic compound biosynthesis and determines the chain-length of VLCFAs in tomato fruit (Leide et al., 2007). The resulting VLCFAs can be converted into primary alcohols and esters by acyl reduction pathway or aldehydes, alkanes, secondary alcohols and ketones by decarbonylation pathway (Kunst and Samuels, 2009). In decarbonylation pathway, CsCER1 and CsWAX2 (CER3) of cucumber and $P a C E R 1$ of sweet cherry was recently shown to play important roles in alkane biosynthesis (Alkio et al., 2012; Wang et al., 2015a,b), while CsCER3 was linked to aldehyde biosynthesis in orange fruit (Wang et al., 2016). Also CsCER4 linked to wax biosynthesis was recently identified in cucumber (Wang W. et al., 2018). Wax triterpenoids and sterols are biosynthesized from squalene produced from mevalonate (MVA) pathway followed by modifications into various compounds (Sawai and Saito, 2011; Thimmappa et al., 2014; Figure 1).

\section{DEVELOPMENTAL REGULATION OF FRUIT CUTICULAR WAX FORMATION}

Tomato is a model species for studying regulation of fleshy fruit development and ripening (Karlova et al., 2014). During the last decades, intensive studies in tomato performed in cuticle formation indicate connections in regulatory network between 


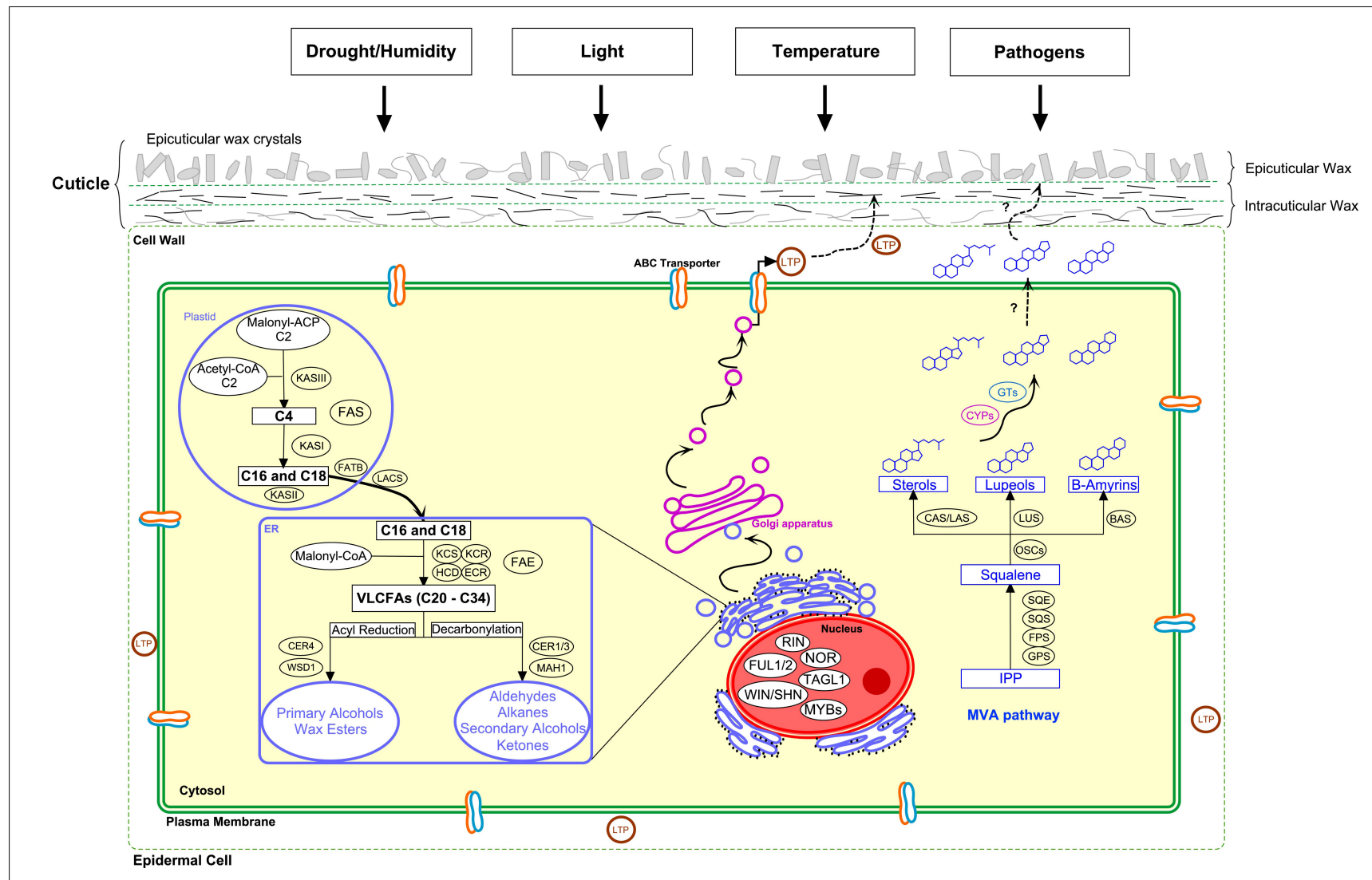

FIGURE 1 | Cuticular wax biosynthesis and interacting environmental factors. Cuticle has an important role as water barrier and in environmental interactions. Biosynthesis of aliphatic wax compounds starts with the generation of fatty acids in plastid by fatty acid synthase complex (FAS). The $\mathrm{C}_{16}$ and $\mathrm{C}_{18}$ precursors are hydrolyzed by acyl-ACP thioesterase (FATB) and converted to CoA thioesters by long chain acyl-CoA synthase (LACS) before transferred to endoplasmic reticulum (ER). In the ER, fatty acids are extended to very-long-chain fatty acids (VLCFAs) by fatty acid elongase (FAE) complex enzymes $\beta$-ketoacyl-CoA synthase (KCS), $\beta$-ketoacyl-CoA reductase (KCR), $\beta$-hydroxyacyl-CoA dehydratase (HCD), and enoyl-CoA reductase (ECR). VLCFAs are modified to primary alcohols by fatty acyl-CoA reductase (CER4) and further to wax esters by wax synthase (WSD1) through acyl reduction pathway. Decarbonylation pathway produces aldehydes, alkanes, secondary alcohols and ketones by enzymes including fatty acyl-CoA reductases (CER1/3) and a midchain alkane hydroxylase (MAH1). The compounds are transported to the plant surface through Golgi network and ABC transporters and by lipid transfer proteins (LTPs). Wax triterpenoids and sterols are derived from squalene that is produced from isopentenyl diphosphate (IPP) through mevalonic acid (MVA) pathway by geranyl pyrophosphate synthase (GPS), farnesyl pyrophosphate synthase (FPS), squalene synthase (SQS), and squalene epoxidase (SQE). Squalene is cyclized by oxidosqualene cyclases (OSCs) including cycloartenol synthase (CAS), lanosterol synthase (LAS), lupeol synthase (LUS), and $\beta$-amyrin synthase (BAS) to produce sterols, lupeols, and amyrins, respectively, which are modified by cytochrome P450 monooxygenases (CYPs) and glycosyltransferases (GTs) before transported to plant surface. TFs important for cuticle development are shown in the nucleus. Modified according to Kunst and Samuels (2009); Sawai and Saito (2011); Lee and Suh (2013); Yeats and Rose (2013); and Thimmappa et al. (2014).

cuticle and fruit development. Transcription factors (TFs) NONRIPENING (NOR), and RIPENING INHIBITOR (RIN) are important regulators of fruit ripening, but tomato nor and rin mutants also show altered fruit cuticular wax profile from early stage throughout the fruit development (Kosma et al., 2010). In addition, other ripening regulators, including FRUITFULL (FUL1,2) and TOMATO AGAMOUS-LIKE1 (TAGL1), have been linked to fruit cuticle development (Bemer et al., 2012; Hen-Avivi et al., 2014; Giménez et al., 2015).

In climacteric fruits, including tomato and apple, plant hormone ethylene acts to initiate and co-ordinate ripening processes, while in many non-climacteric fruits abscisic acid (ABA) has been shown as ripening inducer (Cherian et al., 2014; Karppinen et al., 2018). Both ethylene and ABA signaling seems to play important roles in fruit cuticle biosynthesis
(Ziv et al., 2018). Studies have indicated that ethylene accelerates cuticular wax accumulation in orange and apple (Ju and Bramlage, 2001; Cajuste et al., 2010; Li et al., 2017). The Arabidopsis members of the SHINE (WIN1/SHN1) clade of ethylene responsive factors (ERFs), transducing signal from ethylene, are well-characterized regulators of the cuticular wax biosynthesis (Aharoni et al., 2004; Broun et al., 2004). In tomato, SISHINE3 (SISHN3) was shown to regulate fruit cuticle formation and cuticular lipid biosynthesis (Shi et al., 2013). Also the expression of sweet cherry, apple and mango homologs for WIN1/SHIN1 coincided with fruit cuticle deposition (Alkio et al., 2012; Lashbrooke et al., 2015b; Tafolla-Arellano et al., 2017). Downstream to SISHN3, MYB TF SIMIXTA has been shown to regulate fruit cuticle assembly in tomato (Lashbrooke et al., 2015a; Ewas et al., 2016). Recently, a grape berry-specific 
TABLE 1 | The main cuticular wax compound classes in various fleshy fruits at mature stage and changes during fruit development.

\begin{tabular}{|c|c|c|}
\hline Species & Main compound classes* & References \\
\hline Tomato (Solanum lycopersicum) & $\begin{array}{l}\text { Alkanes ( } n \text {-hentriacontane, } n \text {-nonacosane) } \sim \text {, triterpenoids } \\
\text { (amyrins) } \sim\end{array}$ & $\begin{array}{l}\text { Bauer et al., 2004; Leide et al., 2007, 2011; Saladié } \\
\text { et al., 2007; Mintz-Oron et al., 2008; Kosma et al., } \\
\text { 2010; Petit et al., } 2014\end{array}$ \\
\hline Wild tomato (Solanum spp.) & $\begin{array}{l}\text { Alkanes ( } n \text {-hentriacontane, } n \text {-nonacosane), triterpenoids } \\
\text { (amyrins), esters }\end{array}$ & Yeats et al., 2012 \\
\hline Eggplant (Solanum melongena) & Alkanes ( $n$-hentriacontane), alkanoic acids & Bauer et al., 2005 \\
\hline Apple (Malus × domestica) & $\begin{array}{l}\text { Triterpenoids (ursolic acid) } \downarrow \text {, alkanes ( } n \text {-nonacosane) } \downarrow \text {, } \\
\text { primary and secondary alcohols } \uparrow\end{array}$ & $\begin{array}{l}\text { Belding et al., 1998, 2000; Ju and Bramlage, 2001; } \\
\text { Verardo et al., 2003; Legay et al., 2017; Yang et al., } \\
\text { 2017; Leide et al., 2018 }\end{array}$ \\
\hline Asian pear (Pyrus spp.) & $\begin{array}{l}\text { Alkanes ( } n \text {-hentriacontane, } n \text {-nonacosane) } \downarrow \text {, triterpenoids } \\
\text { ( } \alpha \text {-amyrin) } \uparrow \text {, primary alcohols (triacontanol, } \\
\text { triacontane- } 1,30 \text {-diol) } \uparrow \text {, fatty acids } \uparrow\end{array}$ & $\begin{array}{l}\text { Yin et al., 2011; Li et al., 2014; Heng et al., 2017; } \\
\text { Wu et al., 2017, } 2018\end{array}$ \\
\hline European pear (Pyrus communis) & $\begin{array}{l}\text { Alkanes ( } n \text {-hentriacontane), primary alcohols (triacontanol, } \\
\text { triacontane-1,30-diol) }\end{array}$ & Wu et al., 2018 \\
\hline Sweet cherry (Prunus avium) & $\begin{array}{l}\text { Triterpenoids (ursolic acid) } \downarrow \text {, alkanes ( } n \text {-nonacosane) } \uparrow \text {, } \\
\text { fatty acids }\end{array}$ & $\begin{array}{l}\text { Peschel et al., 2007; Belge et al., 2014a; Rios et al., } \\
2015\end{array}$ \\
\hline Peach (Prunus persica) & $\begin{array}{l}\text { Triterpenoids (ursolic acid, oleanolic acid), alkanes } \\
\text { ( } n \text {-tricosane, } n \text {-pentacosane) }\end{array}$ & Belge et al., 2014b \\
\hline Plum (Prunus domestica) & Secondary alcohols, alkanes (n-nonacosane) & Ismail et al., 1977 \\
\hline Grape (Vitis vinifera) & Triterpenoids (oleanolic acid) $\downarrow$, alcohols $\downarrow$ & $\begin{array}{l}\text { Radler, 1965; Comménil et al., 1997; Casado and } \\
\text { Heredia, 1999; Pensec et al., } 2014\end{array}$ \\
\hline Orange (Citrus sinensis) & $\begin{array}{l}\text { Triterpenoids (friedelin, lupeol) } \uparrow \text {, aldehydes } \uparrow \text {, alkanes } \\
\text { (n-hentriacontane) } \sim \text {, fatty acids } \downarrow\end{array}$ & $\begin{array}{l}\text { Sala et al., 1992; Liu et al., 2012; Wang J. et al., } \\
\text { 2014; Wang et al., } 2016\end{array}$ \\
\hline Satsuma mandarin (Citrus unshiu) & $\begin{array}{l}\text { Aldehydes (octacosanal) } \uparrow, \text { triterpenoids (friedelin) } \sim \text {, } \\
\text { alkanes }(n \text {-nonacosane }) \sim \text {, fatty acids } \sim\end{array}$ & Sala et al., 1992; Wang J. et al., 2014 \\
\hline Grapefruit (Citrus paradisi) & Triterpenoids (friedelin), aldehydes & McDonald et al., 1993; Nordby and McDonald, 1994 \\
\hline Olive (Olea europaea) & $\begin{array}{l}\text { Triterpenoids (oleanolic acid) } \downarrow \text {, primary alcohols } \uparrow \text {, fatty } \\
\text { acid derivatives } \sim\end{array}$ & Bianchi et al., 1992; Huang et al., 2017 \\
\hline Persimmon (Diospyros kaki) & Triterpenoids (ursolic acid, oleanolic acid), alkanes, alcohols & Tsubaki et al., 2013 \\
\hline Pepper (Capsicum annuum) & Triterpenoids (amyrins), alkanes ( $n$-hentriacontane) & $\begin{array}{l}\text { Bauer et al., 2005; Kissinger et al., 2005; Parsons } \\
\text { et al., 2012, } 2013\end{array}$ \\
\hline Cucumber (Cucumis sativus) & Alkanes (n-nonacosane), aldehydes, fatty acids & Wang et al., 2015a,b \\
\hline Blueberry (Vaccinium corymbosum) & Triterpenoids (ursolic acid, oleanolic acid) $\sim, \beta$-diketones $\downarrow$ & Chu et al., 2017, 2018b \\
\hline Blueberry (Vaccinium ashei) & Triterpenoids (ursolic acid) $\uparrow, \beta$-diketones $\downarrow$ & Chu et al., 2017, 2018b \\
\hline Cranberry (Vaccinium macrocarpon) & Triterpenoids (amyrins), aldehydes & Croteau and Fagerson, 1971 \\
\hline Bayberry (Myrica pensylvanica) & Glycerolipids (triacylglycerol, diacylglycerol) & Simpson and Ohlrogge, 2016 \\
\hline
\end{tabular}

* Proportional change in cuticular wax during fruit development is indicated when information available. $\uparrow$, increased proportion; $\downarrow$, decreased proportion; no clear trend. The main compound(s) indicated in parentheses when information available.

ERF VviERF045, resembling SHINE clade members, and Malus AP2/SHEN member McWRI1 were indicated in regulation of cuticular wax biosynthesis (Leida et al., 2016; Hao et al., 2017). A connection between ABA and cuticular wax biosynthesis was demonstrated in orange fruit (Wang et al., 2016). In cucumber, $\mathrm{ABA}$ was shown to induce gene expression involved in cuticle alkane biosynthesis (Wang et al., 2015a,b).

Due to the multiple tasks, maintaining intact cuticle over the fruit development is necessary, but challenging, due to rapid and extensive surface expansion. Cuticular wax deposition starts early in fruit development (Comménil et al., 1997; Casado and Heredia, 2001; Curry, 2005; Domínguez et al., 2008). However, the pattern of wax load varies markedly between species (in contrast to cutin load) and indicates separately regulated wax biosynthesis from cutin biosynthesis (Wang et al., 2016). In many fruits, including apple (Ju and Bramlage, 2001; Lai et al., 2016), orange (Liu et al., 2012; Wang et al., 2016), pear (Li et al., 2014), blueberries (Chu et al., 2018b), bayberry (Simpson and Ohlrogge, 2016), and mango (Tafolla-Arellano et al., 2017), cuticular wax load increases during the fruit development leading to a thick cuticle at maturity. Furthermore, in many fruits, modification of the wax chemical profile and cuticle accumulation, even after harvest has been reported (Ju and Bramlage, 2001; Belge et al., 2014a,b; Tafolla-Arellano et al., 2017; Yang et al., 2017). Tomatoes also have a thick cuticle at maturity but there are clear cultivar-specific variations in cuticle development (España et al., 2014). In cherry tomatoes, cuticular wax is deposited early in fruit development (Domínguez et al., 2008), while in mediumsized tomatoes, such as "Micro Tom" and "Ailsa Craig", the wax amount reaches its maximum level at orange-colored stage (Leide et al., 2007; Mintz-Oron et al., 2008) and in some other cultivars the wax amount increases continuously toward the fruit maturity (Bauer et al., 2004). In tomato, all the wax compound classes, except branched alkanes, accumulate during the cuticular 
wax load (Leide et al., 2007; Mintz-Oron et al., 2008; Kosma et al., 2010). However, in many cases, the continuous wax load leads to changes in the cuticular wax profile during the fruit development (Table 1). For example, in apple, hydrocarbons and triterpenoids predominate in cuticles of young fruits while fatty acids, alcohols and esters contribute mostly to the wax increase during fruit ripening increasing wax greasiness (Ju and Bramlage, 2001; Yang et al., 2017).

High cuticular wax deposition rate at the early stages of fruit development followed by reduction at later stages has been described for sweet cherry (Peschel et al., 2007; Alkio et al., 2012; Lai et al., 2016) and grape (Comménil et al., 1997; Becker and Knoche, 2012; Pensec et al., 2014). The decrease in sweet cherry wax load toward fruit maturity was mainly attributed to the decrease in triterpenoids (Peschel et al., 2007). Similarly, the total triterpenoids decreased during the development of grape berries (Pensec et al., 2014). The role of cuticle as a mechanical support at fruit ripening is important when degrading cell walls cannot sustain the fruit internal pressure. Thus, the inability of the wax deposition to keep in the pace with surface expansion makes ripening fruits vulnerable for micro- and macro-cracking leading to uncontrolled water movement and fungal infections (Comménil et al., 1997; Børve et al., 2000). Cracking is a serious problem in many fruit species, such as tomato and cherries (Domínguez et al., 2012). Recently, an association between cuticular $n$-nonacosane level and cracking tolerance among sweet cherry varieties was described by Rios et al. (2015). Failure in cuticle deposition associated with micro-cracking can cause formation of russeting, a common disorder in fruits, such as apples and pears (Khanal et al., 2013). Improper cuticular wax deposition was shown to be accompanied by the decreased expression of wax biosynthetic genes and MdSHN3 TF in russeted apples (Lashbrooke et al., 2015b; Legay et al., 2015, 2017).

\section{ENVIRONMENTAL REGULATION OF FRUIT WAX BIOSYNTHESIS AND COMPOSITION}

Being a protective barrier on fruit surface, cuticle has a crucial role in the tolerance to various environmental stresses (Figure 1), including osmotic stress (Shepherd and Griffiths, 2006; Xue et al., 2017). Both drought stress and humidity have been shown to affect cuticle deposition. In general, a decrease in cuticle deposition has been detected in plants under high humidity (Tafolla-Arellano et al., 2018). In tomato fruit, decreased cuticle thickness was detected in high humidity, but had no effect on wax accumulation (Leonardi et al., 1999; Domínguez et al., 2012). Instead, plants adapted to water deficit conditions usually have well-developed cuticles in fruits (Crisosto et al., 1994; Barker and Procopiou, 2000; Xue et al., 2017). Regulation of cuticular wax biosynthesis in response to drought stress has been most intensively studied in Arabidopsis but also in tomato and cucumber (Xue et al., 2017). In tomato, overexpression of SISHN1 TF induced expression of wax biosynthetic genes leading to enhanced cuticular wax deposition and droughttolerance compared to control plants (Al-Abdallat et al., 2014).
In cucumber, the expression of fruit-specific cuticular wax genes CsCER1 and CsWAX2 increased under drought and salinity stresses (Wang et al., 2015a,b). Furthermore, transcriptome level studies in drought-sensitive cucumber variety suggested that the decreased expression of cutin, suberin, and wax biosynthetic genes might be responsible for sensitivity to drought (Wang M. et al., 2018).

Both light and temperature can directly change the morphology and properties of fruit epicuticular wax (Schirra et al., 1999; Charles et al., 2008). For example, a post harvest heat treatment at $38^{\circ} \mathrm{C}$ was shown to affect the structure of the epicuticular wax in apple (Roy et al., 1994). However, temperature changes can also modify the biosynthesis of fruit cuticular waxes. Since wax layer is important in maintaining postharvest quality (Lara et al., 2014; Chu et al., 2018a), most temperature treatments have been performed on postharvest fruits. In Malus fruits, low temperature treatment $\left(+4^{\circ} \mathrm{C}\right)$ increased the thickness of cuticular wax compared to control fruits and up-regulated the expression of McWRI1, McKCS, $M c L A C S$, and McWAX leading to the accumulation of alkanes (Hao et al., 2017). Similarly, expression of cucumber fruit-specific CsCER1 and CsWAX2 were induced by low temperature (Wang et al., 2015a,b). Changes in fruit cuticular wax content and composition during cold storage have also been reported for blueberries (Chu et al., 2018b), Asian pears (Wu et al., 2017), grapefruit (Citrus paradisi, Nordby and McDonald, 1991), and sweet cherries (Belge et al., 2014a).

Cuticle is the first barrier to receive light radiation. The increase in thickness of the cuticular wax layer as a response to higher irradiation has been shown in many plant species (Shepherd and Griffiths, 2006; Tafolla-Arellano et al., 2018). In grape berries, the cuticle amount was reported to be higher in sun-exposed berries compared to berries developed in canopy shade (Rosenquist and Morrison, 1989). Also, the spectral quality of light affects the cuticular wax biosynthesis and several reports show that cuticular wax plays a role in the protection against damaging UV-light. Irradiation with enhanced UV-B or UV-C has been demonstrated to increase total amount of cuticular wax and alter wax composition (Tafolla-Arellano et al., 2018). Monochromatic far-red light was shown to stimulate the cuticular wax biosynthesis increasing hydrophobicity of the wax in both tomato and bell pepper fruits during storage (Cozmuta et al., 2016a,b). In grapefruit and mango, interaction of light and temperature conditions affected fruit cuticle accumulation and cuticular wax composition considering difference between fruits growing in interior or exterior canopy (McDonald et al., 1993; Léchaudel et al., 2013).

\section{BIOACTIVITY AND COMMERCIAL POTENTIAL OF WAXES}

Cuticle serves as a primary defense against pathogens and affects susceptibility of fruits to pathogens (Comménil et al., 1997; Saladié et al., 2007; Shi et al., 2013). It was shown in sweet orange and pepper that fruits respond to fungal infections by increasing the cuticle load (Kim et al., 2004; Marques et al., 2012). Agudelo-Romero et al. (2015) reported 
that grape berries infected with Botrytis cinerea accumulated saturated long-chain fatty acids with simultaneous up-regulation of genes related to lipid and wax biosynthesis, including acyl-CoA synthetases (LACSs). A transcriptome analysis of Colletotrichum gloeosporioides infected tomato fruits showed activation of genes linked to the formation of cuticular wax VLCFAs (Alkan et al., 2015). Also, a contact of orange fruit with yeast Kloeckera apiculata was shown to trigger biosynthesis of cuticular waxes and expression of CsKCSs leading to increased wax hydrophobicity and changes in wax morphology (Liu et al., 2014).

In addition to cuticles acting as physical barriers, recent findings suggest that cuticle composition rather than thickness determines fruit susceptibility to pathogens (Reina-Pinto and Yephremov, 2009; Ziv et al., 2018). Fruit cuticular waxes are especially rich sources of triterpenoids, which have clear bioactive properties, such as anticancer, anti-inflammatory, antimicrobial and cardioprotective (Dzubak et al., 2006; Szakiel et al., 2012). He and Liu (2007) isolated triterpenoids from apple peels and reported antiproliferative activity against human cancer cells. The antifungal activity of Asian pear fruit cuticular wax was associated with $n$-alkanes, fatty acids along with triterpenoids (Yin et al., 2011; Chen et al., 2014; Li et al., 2014).

Plant cuticles potentially offer a natural alternative for synthetic waxes. Industrial leftover material in particular, such as peels from juice production, provides raw material for isolating fruit wax compounds. For example, extraction of apple peel pomace using supercritical fluid extraction (SFE) demonstrated the reuse potential of juice industry leftovers as a source for value-added wax ( $\mathrm{Li}$ et al., 2015). Recently, Tedeschi et al.

\section{REFERENCES}

Agudelo-Romero, P., Erban, A., Rego, C., Carbonell-Bejerano, P., Nascimento, T., Sousa, L., et al. (2015). Transcriptome and metabolome reprogramming in Vitis vinifera cv. Trincadeira berries upon infection with Botrytis cinerea. J. Exp. Bot. 66, 1769-1785. doi: 10.1093/jxb/eru517

Aharoni, A., Dixit, S., Jetter, R., Thoenes, E., van Arkel, G., and Pereira, A. (2004). The SHINE clade of AP2 domain transcription factors activates wax biosynthesis, alters cuticle properties, and confers drought tolerance when overexpressed in Arabidopsis. Plant Cell 16, 2463-2480. doi: 10.1105/tpc.104. 022897

Al-Abdallat, A. M., Al-Debei, H. S., Ayad, J. Y., and Hasan, S. (2014). Overexpression of SISHN1 gene improves drought tolerance by increasing cuticular wax accumulation in tomato. Int. J. Mol. Sci. 15, 19499-19515. doi: 10.3390/ ijms151119499

Albert, Z., Ivanics, B., Molnár, A., Miskó, A., Tóth, M., and Papp, I. (2013). Candidate genes of cuticle formation show characteristic expression in the fruit skin of apple. Plant Growth Regul. 70, 71-78. doi: 10.1007/s10725-0129779-y

Alkan, N., Friedlander, G., Ment, D., Prusky, D., and Fluhr, R. (2015). Simultaneous transcriptome analysis of Colletotrichum gloeosporioides and tomato fruit pathosystem reveals novel fungal pathogenicity and fruit defense strategies. New Phytol. 205, 801-815. doi: 10.1111/nph.13087

Alkio, M., Jonas, U., Declercq, M., Van Nocker, S., and Knoche, M. (2014). Transcriptional dynamics of the developing sweet cherry (Prunus avium L.) fruit: sequencing, annotation and expression profiling of exocarp-associated genes. Hortic. Res. 1:11. doi: 10.1038/hortres.2014.11

Alkio, M., Jonas, U., Sprink, T., van Nocker, S., and Knoche, M. (2012). Identification of putative candidate genes involved in cuticle formation in Prunus avium (sweet cherry) fruit. Ann. Bot. 110, 101-112. doi: 10.1093/aob/ $\operatorname{mcs} 087$
(2018) demonstrated the utilization of fatty acids from tomato pomace waste for production of packaging films. Thus, fruit cuticular waxes from industrial waste can provide sources for bioactive compounds and biodegradable products for the use in pharmaceuticals, cosmetics, packaging, nanocoatings, and the food industry.

\section{AUTHOR CONTRIBUTIONS}

All authors (PT, NN, ALH, HH, IM, LJ, and KK) have participated in preparation of the manuscript and have accepted the final version.

\section{FUNDING}

This work was financially supported by I4 future doctoral program, hosted at the University of Oulu: Novel Imaging and Characterization Methods in Bio, Medical, and Environmental Research and Technology Innovations, which is the European Union's Horizon 2020 Research and Innovation Programme under the Marie Sklodowska-Curie action co-funded international, interdisciplinary and inter-sectoral doctoral programme (grant number 713606 to PT's doctoral studies), and by the grant IR16-020 Natural Wax of Arctic Berries as our Treasure - WAX (project number 20201089) supported by Interreg Nord and grant RMF16-026 Troms Fylkeskommune and NIBIO.

Barker, E. A., and Procopiou, J. (2000). The leaf and fruit cuticles of selected drought tolerant plants. Acta Hort. 527, 85-93. doi: 10.17660/ActaHortic.2000. 527.9

Barthlott, W., Mail, M., Bhushan, B., and Koch, K. (2017). Plant surfaces: structures and functions for biomimetic innovations. Nano Micro Lett. 9:23. doi: 10.1007/ s40820-016-0125-1

Bauer, S., Schulte, E., and Thier, H. P. (2004). Composition of the surface wax from tomatoes. II. Quantification of the components at the ripe red stage and during ripening. Eur. Food Res. Technol. 219, 487-491. doi: 10.1007/s00217-0040944-z

Bauer, S., Schulte, E., and Thier, H. P. (2005). Composition of the surface waxes from bell pepper and eggplant. Eur. Food Res. Technol. 220, 5-10. doi: 10.1007/ s00217-004-1046-7

Becker, T., and Knoche, M. (2012). Deposition, strain, and microcracking of the cuticle in developing 'Riesling' grape berries. Vitis 51, 1-6.

Belding, R. D., Blankenship, S. M., Young, E., and Leidy, R. B. (1998). Composition and variability of epicuticular waxes in apple cultivars. J. Am. Soc. Hort. Sci. 123, 348-356. doi: 10.21273/JASHS.123.3.348

Belding, R. D., Sutton, T. B., Blankenship, S. M., and Young, E. (2000). Relationship between apple fruit epicuticular wax and growth of Peltaster fructicola and Leptodontidium elatius, two fungi that cause sooty blotch disease. Plant Dis. 84, 767-772. doi: 10.1094/PDIS.2000.84.7.767

Belge, B., Llovera, M., Comabella, E., Gatius, F., Guillén, P., Graell, J., et al. (2014a). Characterization of cuticle composition after cold storage of "celeste" and "somerset" sweet cherry fruit. J. Agric. Food Chem. 62, 8722-8729. doi: $10.1021 /$ jf502650t

Belge, B., Llovera, M., Comabella, E., Graell, J., and Lara, I. (2014b). Fruit cuticle composition of a melting and a nonmelting peach cultivar. J. Agric. Food Chem. 62, 3488-3495. doi: 10.1021/jf5003528

Bemer, M., Karlova, R., Ballester, A. R., Tikunov, Y. M., Bovy, A. G., WoltersArts, M., et al. (2012). The tomato FRUITFULL homologs TDR4/FUL1 and 
MBP7/FUL2 regulate ethylene-independent aspects of fruit ripening. Plant Cell 24, 4437-4451. doi: 10.1105/tpc.112.103283

Bernard, A., and Joubès, J. (2013). Arabidopsis cuticular waxes: advances in synthesis, export and regulation. Prog. Lipid Res. 52, 110-129. doi: 10.1016/j. plipres.2012.10.002

Bianchi, G., Murelli, C., and Vlahov, G. (1992). Surface waxes from olive fruits. Phytochemistry 31, 3503-3506. doi: 10.1016/0031-9422(92)83716-C

Borisjuk, N., Hrmova, M., and Lopato, S. (2014). Transcriptional regulation of cuticle biosynthesis. Biotechnol. Adv. 32, 526-540. doi: 10.1016/j.biotechadv. 2014.01.005

Børve, J., Sekse, L., and Stensvand, A. (2000). Cuticular fractures promote postharvest fruit rot in sweet cherries. Plant Dis. $84,1180-1184$. doi: 10.1094/ PDIS.2000.84.11.1180

Broun, P., Poindexter, P., Osborne, E., Jiang, C. Z., and Riechmann, J. L. (2004). WIN1, a transcriptional activator of epidermal wax accumulation in Arabidopsis. Proc. Natl. Acad. Sci. 101, 4706-4711. doi: 10.1073/pnas. 0305574101

Cajuste, J. F., González-Candelas, L., Veyrat, A., García-Breijo, F. J., ReigArmiñana, J., and Lafuente, M. T. (2010). Epicuticular wax content and morphology as related to ethylene and storage performance of 'Navelate' orange fruit. Postharvest. Biol. Technol. 55, 29-35. doi: 10.1016/j.postharvbio.2009. 07.005

Casado, C. G., and Heredia, A. (1999). Structure and dynamics of reconstituted cuticular waxes of grape berry cuticle (Vitis vinifera L.). J. Exp. Bot. 50, 175-182. doi: $10.1093 / \mathrm{jxb} / 50.331 .175$

Casado, C. G., and Heredia, A. (2001). Ultrastructure of the cuticle during growth of the grape berry (Vitis vinifera). Physiol. Plant. 111, 220-224. doi: 10.1034/j. 1399-3054.2001.1110213.x

Charles, M. T., Makhlouf, J., and Arul, J. (2008). Physiological basis of UV-C induced resistance to Botrytis cinerea in tomato fruit: II. modification of fruit surface and changes in fungal colonization. Postharv. Biol. Technol. 47, 21-26. doi: 10.1016/j.postharvbio.2007.05.014

Chen, S., Li, Y., Bi, Y., Yin, Y., Ge, Y., and Wang, Y. (2014). Solvent effects on the ultrastructure and chemical composition of cuticular wax and its potential bioactive role against Alternaria alternata in pingguoli pear. J. Integr. Agr. 13, 1137-1145. doi: 10.1016/S2095-3119(13)60374-3

Cherian, S., Figueroa, C. R., and Nair, H. (2014). Movers and shakers' in the regulation of fruit ripening: a cross-dissection of climacteric versus nonclimacteric fruit. J. Exp. Bot. 65, 4705-4722. doi: 10.1093/jxb/eru280

Chu, W., Gao, H., Cao, S., Fang, X., Chen, H., and Xiao, S. (2017). Composition and morphology of cuticular wax in blueberry (Vaccinium spp.) fruits. Food Chem. 219, 436-442. doi: 10.1016/j.foodchem.2016.09.186

Chu, W., Gao, H., Chen, H., Fang, X., and Zheng, Y. (2018a). Effects of cuticular wax on the postharvest quality of blueberry fruit. Food Chem. 239, 68-74. doi: 10.1016/j.foodchem.2017.06.024

Chu, W., Gao, H., Chen, H., Wu, W., and Fang, X. (2018b). Changes in cuticular wax composition of two blueberry cultivars during fruit ripening and postharvest cold storage. J. Agric. Food Chem. 66, 2870-2876. doi: 10.1021/acs. jafc. $7 \mathrm{~b} 05020$

Comménil, P., Brunet, L., and Audran, J. C. (1997). The development of the grape berry cuticle in relation to susceptibility to bunch rot disease. J. Exp. Bot. 48, 1599-1607. doi: 10.1093/jxb/48.8.1599

Cozmuta, A. M., Cozmuta, L. M., Peter, A., Nicula, C., Crisan, L., Vulpoi, A., et al. (2016a). The influence of far-red light on the attributes of green bell pepper fruits (Capsicum annuum L.) during storage. The Annals of the University Dunarea de Jos of Galati Fascicle VI - Food Technology 40, 98-118.

Cozmuta, A. M., Cozmuta, L. M., Peter, A., Nicula, C., Vosgan, Z., Giurgiulescu, L., et al. (2016b). Effect of monochromatic far-red light on physical-nutritionalmicrobiological attributes of red tomatoes during storage. Sci. Hortic. 211, 220-230. doi: 10.1016/j.scienta.2016.08.031

Crisosto, C. H., Johnson, R. S., Luza, J. G., and Crisosto, G. M. (1994). Irrigation regimes affect fruit soluble solids concentration and rate of water loss of 'O'Henrys' peaches. HortScience 29, 1169-1171. doi: 10.21273/HORTSCI.29.10. 1169

Croteau, R., and Fagerson, I. S. (1971). The chemical composition of the cuticular wax of cranberry. Phytochemistry 10, 3239-3245. doi: 10.1016/S0031-9422(00) 97379-5
Curry, E. A. (2005). Ultrastructure of epicutucular wax aggregates during fruit development in apple (Malus domestica Borkh.). J. Hortic. Sci. Biotech. 80, 668-676. doi: 10.1080/14620316.2005.11511996

Domínguez, E., Fernández, M. D., Hernández, J. C. L., Parra, J. P., España, L., Heredia, A., et al. (2012). Tomato fruit continues growing while ripening, affecting cuticle properties and cracking. Physiol. Plant. 146, 473-486. doi: 10.1111/j.1399-3054.2012.01647.x

Domínguez, E., López-Casado, G., Cuartero, J., and Heredia, A. (2008). Development of fruit cuticle in cherry tomato (Solanum lycopersicum). Funct. Plant Biol. 35, 403-411. doi: 10.1071/FP08018

Dzubak, P., Hajduch, M., Vydra, D., Hustova, A., Kvasnica, M., Biedermann, D., et al. (2006). Pharmacological activities of natural triterpenoids and their therapeutic implications. Nat. Prod. Rep. 23, 394-411. doi: 10.1039/ b515312n

España, L., Heredia-Guerrero, A. J., Segado, P., Benítez, J. J., Heredia, A., and Domínguez, E. (2014). Biomechanical properties of the tomato (Solanum lycopersicum) fruit cuticle during development are modulated by changes in the relative amounts of its components. New Phytol. 202, 790-802. doi: 10.1111/ nph.12727

Ewas, M., Gao, Y., Wang, S., Liu, X., Zhang, H., Nishawy, E. M. E., et al. (2016). Manipulation of SIMXI for enhanced carotenoids accumulation and drought resistance in tomato. Sci. Bull. 61, 1413-1418. doi: 10.1007/s11434-016-1108-9

Fernández, V., Guzmán-Delgado, P., Graça, J., Santos, S., and Gil, L. (2016). Cuticle structure in relation to chemical composition: re-assessing the prevailing model. Front. Plant Sci. 7:427. doi: 10.3389/fpls.2016.00427

Giménez, E., Dominguez, E., Pineda, B., Heredia, A., Moreno, V., Lozano, R., et al. (2015). Transcriptional activity of the MADS box ARLEQUIN/TOMATO AGAMOUS-LIKE1 gene is required for cuticle development of tomato fruit. Plant Physiol. 168, 1036-1048. doi: 10.1104/pp.15.00469

Hao, S., Ma, Y., Zhao, S., Ji, Q., Zhang, K., Yang, M., et al. (2017). McWRI1, a transcription factor of the AP2/SHEN family, regulates the biosynthesis of the cuticular waxes on the apple fruit surface under low temperature. PLoS One 12:e0186996. doi: 10.1371/journal.pone.0186996

He, X. J., and Liu, R. H. (2007). Triterpenoids isolated from apple peels have potent antiproliferative activity and may be partially responsible for apple's anticancer activity. J. Agric. Food Chem. 55, 4366-4370. doi: 10.1021/jf063563o

Hen-Avivi, S., Lashbrooke, J., Costa, F., and Aharoni, A. (2014). Scratching the surface: genetic regulation of cuticle assembly in fleshy fruit. J. Exp. Bot. 65, 4653-4664. doi: 10.1093/jxb/eru225

Heng, W., Huang, H., Li, F., Hou, Z., and Zhu, L. (2017). Comparative analysis of the structure, suberin and wax composition and key gene expression in the epidermis of 'Dangshansuli' pear and its russet mutant. Acta Physiol. Plant. 39:150. doi: 10.1007/s11738-017-2443-4

Huang, H., Burghardt, M., Schuster, A. C., Leide, J., Lara, I., and Riederer, M. (2017). Chemical composition and water permeability of fruit and leaf cuticles of Olea europaea L. J. Argic. Food Chem. 65, 8790-8797. doi: 10.1021/acs.jafc. $7 \mathrm{~b} 03049$

Ismail, H. M., Brown, G. A., Tucknott, O. G., Holloway, P. J., and Williams, A. A. (1977). Nonanal in epicuticular wax of golden egg plums (Prunus domestica). Phytochemistry 16, 769-770. doi: 10.1016/S0031-9422(00)89254-7

Ju, Z., and Bramlage, W. J. (2001). Developmental changes of cuticular constituents and their association with ethylene during fruit ripening in 'delicious' apples. Postharvest Biol. Technol. 21, 257-263. doi: 10.1016/S0925-5214(00)00156-3

Karlova, R., Chapman, N., David, K., Angenent, G. C., Seymour, G. B., and de Maagd, R. A. (2014). Transcriptional control of fleshy fruit development and ripening. J. Exp. Bot. 65, 4527-4541. doi: 10.1093/jxb/eru316

Karppinen, K., Tegelberg, P., Häggman, H., and Jaakola, L. (2018). Abscisic acid regulates anthocyanin biosynthesis and gene expression associated with cell wall modification in ripening bilberry (Vaccinium myrtillus L.) fruits. Front. Plant Sci. 9:1259. doi: 10.3389/fpls.2018.01259

Khanal, B. P., Grimm, E., and Knoche, M. (2013). Russeting in apple and pear: a plastic periderm replaces a stiff cuticle. AoB Plants 5:pls048. doi: 10.1093/ aobpla/pls048

Kim, K. H., Yoon, J. B., Park, H. G., Park, E. W., and Kim, Y. H. (2004). Structural modifications and programmed cell death of chili pepper fruit related to resistance responses to Colletotrichum gloeosporioides infection. Phytopathology 94, 1295-1304. doi: 10.1094/PHYTO.2004.94.12.1295 
Kissinger, M., Tuvia-Alkalai, S., Shalom, Y., Fallik, E., Elkind, Y., Jenks, M. A., et al. (2005). Characterization of physiological and biochemical factors associated with postharvest water loss in ripe pepper fruit during storage. J. Am. Soc. Hort. Sci. 130, 735-741. doi: 10.21273/JASHS.130.5.735

Koch, K., and Ensikat, H. J. (2008). The hydrophobic coatings of plant surfaces: epicuticular wax crystals and their morphologies, crystallinity and molecular self-assembly. Micron 39, 759-772. doi: 10.1016/j.micron.2007.11.010

Kosma, D. K., Parsons, E. P., Isaacson, T., Lu, S., Rose, J. K. C., and Jenks, M. A. (2010). Fruit cuticle lipid composition during development in tomato ripening mutants. Physiol. Plant. 139, 107-117. doi: 10.1111/j.1399-3054.2009.01342.x

Kunst, L., and Samuels, L. (2009). Plant cuticles shine: advances in wax biosynthesis and export. Curr. Opin. Plant Biol. 12, 721-727. doi: 10.1016/j.pbi.2009.09.009

Lai, X., Khanal, B. P., and Knoche, M. (2016). Mismatch between cuticle deposition and area expansion in fruit skins allows potentially catastrophic buildup of elastic strain. Planta 244, 1145-1156. doi: 10.1007/s00425-016-2572-9

Lara, I., Belge, B., and Goulao, L. F. (2014). The fruit cuticle as a modulator of postharvest quality. Posharvest Biol. Technol. 87, 103-112. doi: 10.1016/j. postharvbio.2013.08.012

Lara, I., Belge, B., and Goulao, L. F. (2015). A focus on the biosynthesis and composition of cuticle in fruits. J. Agric. Food Chem. 63, 4005-4019. doi: 10. 1021 acs.jafc.5b00013

Lashbrooke, J., Adato, A., Lotan, O., Alkan, N., Tsimbalist, T., Rechav, K., et al. (2015a). The tomato MIXTA-like transcription factor coordinates fruit epidermis conical cell development and cuticular lipid biosynthesis and assembly. Plant Physiol. 169, 2553-2571. doi: 10.1104/pp.15.01145

Lashbrooke, J., Aharoni, A., and Costa, F. (2015b). Genome investigation suggests MdSHN3, an APETALA2-domain transcription factor gene, to be a positive regulator of apple fruit cuticle formation and an inhibitor of russet development. J. Exp. Bot. 66, 6579-6589. doi: 10.1093/jxb/erv366

Léchaudel, M., Lopez-Lauri, F., Vidal, V., Sallanon, H., and Joas, J. (2013). Response of the physiological parameters of mango fruit (transpiration, water relations and antioxidant system) to its light and temperature environment. J. Plant Physiol. 170, 567-576. doi: 10.1016/j.jplph.2012.11.009

Lee, S. B., and Suh, M. C. (2013). Recent advances in cuticular wax biosynthesis and its regulation in Arabidopsis. Mol. Plant 6, 246-249. doi: 10.1093/mp/sss 159

Legay, S., Cocco, E., André, C. M., Guignard, C., Hausman, J. F., and Guerriero, G. (2017). Differential lipid composition and gene expression in the semi-russeted “cox orange pippin" apple variety. Front. Plant Sci. 8:1656. doi: 10.3389/fpls. 2017.01656

Legay, S., Guerriero, G., Deleruelle, A., Lateur, M., Evers, D., André, C. M., et al. (2015). Apple russeting as seen through the RNA-seq lens: strong alterations in the exocarp cell wall. Plant Mol. Biol. 88, 21-40. doi: 10.1007/s11103-0150303-4

Leida, C., Dal Rì, A., Dalla Costa, L., Gómez, M. D., Pompili, V., Sonego, P., et al. (2016). Insights into the role of the berry-specific ethylene responsive factor VviERF045. Front. Plant Sci. 7:1793. doi: 10.3389/fpls.2016.01793

Leide, J., de Souza, A. X., Papp, I., and Riederer, M. (2018). Specific characteristics of the apple fruit cuticle: Investigations of early and late season cultivars 'prima' and 'florina' (Malus domestica Borkh.). Sci. Hortic. 229, 137-147. doi: 10.1016/j. scienta.2017.10.042

Leide, J., Hildebrandt, U., Reussing, K., Riederer, M., and Vogg, G. (2007). The developmental pattern of tomato fruit wax accumulation and its impact on cuticular transpiration barrier properties: effects of a deficiency in a $\beta$-ketoacylcoenzyme A synthase (LeCER6). Plant Physiol. 144, 1667-1679. doi: 10.1104/ pp.107.099481

Leide, J., Hildebrandt, U., Vogg, G., and Riederer, M. (2011). The positional sterile (ps) mutation affects cuticular transpiration and wax biosynthesis of tomato fruits. J. Plant Physiol. 168, 871-877. doi: 10.1016/j.jplph.2010.11.014

Leonardi, C., Baille, A., and Guichard, S. (1999). Effects of fruit characteristics and climatic conditions on tomato transpiration in a greenhouse. J. Hortic. Sci. Biotech. 74, 748-756. doi: 10.1080/14620316.1999.11511183

Li, F., Min, D., Song, B., Shao, S., and Zhang, X. (2017). Ethylene effects on apple fruit cuticular wax composition and content during cold storage. Postharvest Biol. Technol. 134, 98-105. doi: 10.1016/j.postharvbio.2017.08.011

Li, J., Guo, Y., Li, Z., Lin, Y., Liu, L., Zhang, X., et al. (2015). Supercritical carbon dioxide and hexane extraction of wax from apple peel pomace: content, composition, and thermal properties. Sep. Sci. Technol. 50, 2230-2237. doi: 10.1080/01496395.2015.1020951
Li, Y., Yin, Y., Chen, S., Bi, Y., and Ge, Y. (2014). Chemical composition of cuticular waxes during fruit development of Pingguoli pear and their potential role on early events of Alternaria alternata infection. Funct. Plant Biol. 41, 313-320. doi: 10.1071/FP13184

Liu, D., Yang, L., Zheng, Q., Wang, Y., Wang, M., Zhuang, X., et al. (2015). Analysis of cuticular wax constituents and genes that contribute to the formation of 'glossy Newhall', a spontaneous bud mutant from the wild-type 'Newhall' navel orange. Plant Mol. Biol. 88, 573-590. doi: 10.1007/s11103-015-0343-9

Liu, D. C., Zeng, Q., Ji, Q. X., Liu, C. F., Liu, S. B., and Liu, Y. (2012). A comparison of the ultrastructure and composition of fruits' cuticular wax from the wild-type 'Newhall' navel orange (Citrus sinensis [L.] Osbeck cv. Newhall) and its glossy mutant. Plant Cell Rep. 31, 2239-2246. doi: 10.1007/s00299-012-1333-x

Liu, P., Hao, H., and Long, C. (2014). The effects of Kloeckera apiculata on the cuticular waxes of navel orange fruit. Biol. Control 73, 16-22. doi: 10.1016/j. biocontrol.2014.03.006

Marques, J. P. R., Spósito, M. B., Mello, A. F. S., Amorim, L., Mondin, M., and Appezzato-da-Glória, B. (2012). Histopathology of black spot symptoms in sweet oranges. Eur. J. Plant Pathol. 133, 439-448. doi: 10.1007/s10658-0119917-9

Martin, L. B. B., and Rose, J. K. C. (2014). There's more than one way to skin a fruit: formation and functions of fruit cuticles. J. Exp. Bot. 65, 4639-4651. doi: 10.1093/jxb/eru301

Matas, A. J., Yeats, T. H., Buda, G. J., Zheng, Y., Chatterjee, S., Tohge, T., et al. (2011). Tissue- and cell-type specific transcriptome profiling of expanding tomato fruit provides insights into metabolic and regulatory specialization and cuticle formation. Plant Cell 23, 3893-3910. doi: 10.1105/tpc.111.091173

McDonald, R. E., Nordby, H. E., and McCollum, T. G. (1993). Epicuticular wax morphology and composition are related to grapefruit chilling injury. HortScience 28, 311-312. doi: 10.21273/HORTSCI.28.4.311

Mintz-Oron, S., Mandel, T., Rogachev, I., Feldberg, L., Lotan, O., Yativ, M., et al. (2008). Gene expression and metabolism in tomato fruit surface tissues. Plant Physiol. 147, 823-851. doi: 10.1104/pp.108.116004

Moggia, C., Graell, J., Lara, I., Schmeda-Hirschmann, G., Thomas-Valdés, S., and Lobos, G. A. (2016). Fruit characteristics and cuticle triterpenes as related to postharvest quality of highbush blueberries. Sci. Hortic. 211, 449-457. doi: 10.1016/j.scienta.2016.09.018

Nordby, H. E., and McDonald, R. E. (1991). Relationship of epicuticular wax composition of grapefruit to chilling injury. J. Agric. Food Chem. 39, 957-962. doi: 10.1021/jf00005a032

Nordby, H. E., and McDonald, R. E. (1994). Friedelin, the major component of grapefruit epicuticular wax. J. Agric. Food Chem. 42, 708-713. doi: 10.1021/ jf00039a021

Parsons, E. P., Popopvsky, S., Lohrey, G. T., Alkalai-Tuvia, S., Perzelan, Y., Bosland, P., et al. (2013). Fruit cuticle lipid composition and water loss in a diverse collection of pepper (Capsicum). Physiol. Plant. 149, 160-174. doi: 10.1111/ppl.12035

Parsons, E. P., Popopvsky, S., Lohrey, G. T., Lü, S., Alkalai-Tuvia, S., Perzelan, Y., et al. (2012). Fruit cuticle lipid composition and fruit post-harvest water loss in an advanced backcross generation of pepper (Capsicum sp.). Physiol. Plantarum 146, 15-25. doi: 10.1111/j.1399-3054.2012.01592.x

Pensec, F., Pączkowski, C., Grabarczyk, M., Woźniak, A., Bénard-Gellon, M., Bertsch, C., et al. (2014). Changes in the triterpenoid content of cuticular waxes during fruit ripening of eight grape (Vitis vinifera) cultivars grown in the upper Rhine valley. J. Agric. Food. Chem. 62, 7998-8007. doi: 10.1021/jf502033s

Peschel, S., Franke, R., Schreiber, L., and Knoche, M. (2007). Composition of the cuticle of developing sweet cherry fruit. Phytochemistry 68, 1017-1025. doi: 10.1016/j.phytochem.2007.01.008

Petit, J., Bres, C., Just, D., Garcia, V., Mauxion, J. P., Marion, D., et al. (2014). Analyses of tomato fruit brightness mutants uncover both cutin-deficient and cutin-abundant mutants and a new hypomorphic allele of GDSL Lipase. Plant Physiol. 164, 888-906. doi: 10.1104/pp.113.232645

Petit, J., Bres, C., Mauxion, J. P., Bakan, B., and Rothan, C. (2017). Breeding for cuticle-associated traits in crops species: traits, targets, and strategies. J. Exp. Bot. 68, 5369-5387. doi: 10.1093/jxb/erx341

Radler, F. (1965). The surface waxes of the sultana vine (Vitis vinifera cv. Thompson Seedless). Aust. J. Biol. Sci. 18, 1045-1065. doi: 10.1071/BI9651045

Reina-Pinto, J. J., and Yephremov, A. (2009). Surface lipids and plant defenses. Plant Physiol. Biochem. 47, 540-549. doi: 10.1016/j.plaphy.2009.01.004 
Riederer, M., and Schreiber, L. (2001). Protecting against water loss: analysis of the barrier properties of plant cuticles. J. Exp. Bot. 52, 2023-2032. doi: 10.1093/ jexbot/52.363.2023

Rios, J. C., Robledo, F., Schreiber, L., Zeisler, V., Lang, E., Carrasco, B., et al. (2015). Association between the concentration of n-alkanes and tolerance to cracking in commercial varieties of sweet cherry fruits. Sci. Hortic. 197, 57-65. doi: 10.1016/j.scienta.2015.10.037

Rosenquist, J. K., and Morrison, J. C. (1989). Some factors affecting cuticle and wax accumulation on grape berries. Am. J. Enol. Vitic. 40, 241-244.

Roy, S., Conway, W. S., Watada, A. E., Sams, C. E., Erbe, E. F., and Wergin, W. P. (1994). Heat treatment affects epicuticular wax structure and postharvest calcium uptake in 'golden delicious' apples. HortScience 29, 1056-1058. doi: 10.21273/HORTSCI.29.9.1056

Sala, J. M., Lafuente, T., and Cuñat, P. (1992). Content and chemical composition of epicuticular wax of 'Navelina' oranges and 'Satsuma' mandarins as related to rindstaining of fruit. J. Sci. Food. Agric. 59, 489-495. doi: 10.1002/jsfa. 2740590411

Saladié, M., Matas, A. J., Isaacson, T., Jenks, M. A., Goodwin, S. M., Niklas, K. J., et al. (2007). A reevaluation of the key factors that influence tomato fruit softening and integrity. Plant Physiol. 144, 1012-1028. doi: 10.1104/pp.107. 097477

Sawai, S., and Saito, K. (2011). Triterpenoid biosynthesis and engineering in plants. Front. Plant Sci. 2:25. doi: 10.3389/fpls.2011.00025

Schirra, M., D’hallewin, G., Inglese, P., and La Mantia, T. (1999). Epicuticular changes and storage potential of cactus pear [Opuntia ficus-indica Miller (L.)] fruit following gibberellic acid and preharvest sprays and postharvest heat treatment. Postharvest Biol. Technol. 17, 79-88. doi: 10.1016/S0925-5214(99) 00043-5

Shepherd, T., and Griffiths, D. W. (2006). The effects of stress on plant cuticular waxes. New Phytol. 171, 469-499. doi: 10.1111/j.1469-8137.2006.01826.x

Shi, J. X., Adato, A., Alkan, N., He, Y., Lashbrooke, J., Matas, A. J., et al. (2013). The tomato SISHINE3 transcription factor regulates fruit cuticle formation and epidermal patterning. New Phytol. 197, 468-480. doi: 10.1111/nph.12032

Simpson, J. P., and Ohlrogge, J. B. (2016). A novel pathway for triacylglycerol biosynthesis is responsible for the accumulation of massive quantities of glycerolipids in the surface wax of bayberry (Myrica pensylvanica) fruit. Plant Cell 28, 248-264. doi: 10.1105/tpc.15.00900

Szakiel, A., Pạczkowski, C., Pensec, F., and Bertsch, C. (2012). Fruit cuticular waxes as a source of biologically active triterpenoids. Phytochem. Rev. 11, 263-284. doi: 10.1007/s11101-012-9241-9

Tafolla-Arellano, J. C., Báez-Sañudo, R., and Tiznado-Hernández, M. E. (2018). The cuticle as a key factor in the quality of horticultural crops. Sci. Hortic. 232, 145-152. doi: 10.1016/j.scienta.2018.01.005

Tafolla-Arellano, J. C., Zheng, Y., Sun, H., Jiao, C., Ruiz-May, E., Hernández-Oñate, M. A., et al. (2017). Transcriptome analysis of mango (Mangifera indica L.) fruit epidermal peel to identify putative cuticle-associated genes. Sci. Rep. 7:46163. doi: $10.1038 /$ srep46163

Tedeschi, G., Benitez, J. J., Ceseracciu, L., Dastmalchi, K., Itin, B., Stark, R. E., et al. (2018). Sustainable fabrication of plant cuticle-like packaging films from tomato pomace agro-waste, beeswax, and alginate. ACS Sustain. Chem. Eng. 6, 14955-14966. doi: 10.1021/acssuschemeng.8b03450

Thimmappa, R., Geisler, K., Louveau, T., O’Maille, P., and Osbourn, A. (2014). Triterpene biosynthesis in plants. Annu. Rev. Plant Biol. 65, 225-257. doi: 10.1146/annurev-arplant-050312-120229

Tsubaki, S., Sugimura, K., Teramoto, Y., Yonemori, K., and Azuma, J. (2013). Cuticular membrane of Fuyu persimmon fruit is strengthened by triterpenoid nano-fillers. PLoS One 8:e75275. doi: 10.1371/journal.pone.0075275

Verardo, G., Pagani, E., Geatti, P., and Martinuzzi, P. (2003). A thorough study of the surface wax of apple fruits. Anal. Bioanal. Chem. 376, 659-667. doi: 10.1007/s00216-003-1945-7

Vogg, G., Fischer, S., Leide, J., Emmanuel, E., Jetter, R., Levy, A. A., et al. (2004). Tomato fruit cuticular waxes and their effect on transpiration barrier properties: functional characterization of a mutant deficient in a very-long-chain fatty acid $\beta$-ketoacyl-CoA synthase. J. Exp. Bot. 55, 1401-1410. doi: 10.1093/jxb/erh149

Wang, J., Sun, L., Xie, L., He, Y., Luo, T., Sheng, L., et al. (2016). Regulation of cuticle formation during fruit development and ripening in 'Newhall' navel orange (Citrus sinensis Osbeck) revealed by transcriptomic and metabolomic profiling. Plant Sci. 243, 131-144. doi: 10.1016/j.plantsci.2015.12.010

Wang, M., Jiang, B., Peng, Q., Liu, W., He, X., Liang, Z., et al. (2018). Transcriptome analyses in different cucumber cultivars provide novel insights into drought stress responses. Int. J. Mol. Sci. 19:2067. doi: 10.3390/ijms19072067

Wang, W., Wang, S., Li, M., and Hou, L. (2018). Cloning and expression analysis of Cucumis sativus L. CER4 involved in cuticular wax biosynthesis in cucumber. Biotechnol. Biotechnol. Equip. 32, 1113-1118. doi: 10.1080713102818.2018. 1499444

Wang, W., Liu, X., Gai, X., Ren, J., Liu, X., Cai, Y., et al. (2015a). Cucumis sativus L. WAX2 plays a pivotal role in wax biosynthesis, influencing pollen fertility and plant biotic and abiotic stress responses. Plant Cell Physiol. 56, 1339-1354. doi: $10.1093 / \mathrm{pcp} / \mathrm{pcv052}$

Wang, W., Zhang, Y., Xu, C., Ren, J., Liu, X., Black, K., et al. (2015b). Cucumber ECERIFERUM1 (CsCER1), which influences the cuticle properties and drought tolerance of cucumber, plays a key role in VLC alkanes biosynthesis. Plant Mol. Biol. 87, 219-233. doi: 10.1007/s11103-014-0271-0

Wang, Y., Dai, M., Zhang, S., and Shi, Z. (2014). Exploring candidate genes for pericarp russet pigmentation of sand pear (Pyrus pyrifolia) via RNA-seq data in two genotypes contrasting for pericarp color. PLoS One 9:e83675. doi: 10.1371/ journal.pone. 0083675

Wang, J., Hao, H., Liu, R., Ma, Q., Xu, J., Chen, F., et al. (2014). Comparative analysis of surface wax in mature fruits between Satsuma mandarin (Citrus unshiu) and 'Newhall' navel orange (Citrus sinensis) from the perspective of crystal morphology, chemical composition and key gene expression. Food Chem. 153, 177-185. doi: 10.1016/j.foodchem.2013.12.021

Wu, X., Yin, H., Chen, Y., Li, L., Wang, Y., Hao, P., et al. (2017). Chemical composition, crystal morphology and key gene expression of cuticular waxes of Asian pears at harvest and after storage. Postharvest Biol. Technol. 132, 71-80. doi: 10.1016/j.postharvbio.2017.05.007

Wu, X., Yin, H., Shi, Z., Chen, Y., Qi, K., Qiao, X., et al. (2018). Chemical composition and crystal morphology of epicuticular wax in mature fruits of 35 pear (Pyrus spp.) cultivars. Front. Plant Sci. 9:679. doi: 10.3389/fpls.2018. 00679

Xue, D., Zhang, X., Lu, X., Chen, G., and Chen, Z. (2017). Molecular and evolutionary mechanisms of cuticular wax for plant drought tolerance. Front. Plant Sci. 8:621. doi: 10.3389/fpls.2017.00621

Yang, Y., Zhou, B., Zhang, J., Wang, C., Liu, C., Liu, Y., et al. (2017). Relationship between cuticular waxes and skin greasiness of apples during storage. Postharvest Biol. Technol. 131, 55-67. doi: 10.1016/j.postharvbio.2017. 05.006

Yeats, T. H., Buda, G. J., Wang, Z., Chehanovsky, N., Moyle, L. C., Jetter, R., et al. (2012). The fruit cuticles of wild tomato species exhibit architectural and chemical diversity, providing a new model for studying the evolution of cuticle function. Plant J. 69, 655-666. doi: 10.1111/j.1365-313X.2011.04820.x

Yeats, T. H., and Rose, J. K. C. (2013). The formation and function of plant cuticles. Plant Physiol. 163, 5-20. doi: 10.1104/pp.113.222737

Yin, Y., Bi, Y., Chen, S., Li, Y., Wang, Y., Ge, Y., et al. (2011). Chemical composition and antifungal activity of cuticular wax isolated from Asian pear fruit (cv. Pingguoli). Sci. Hortic. 129, 577-582. doi: 10.1016/j.scienta.2011. 04.028

Ziv, C., Zhao, Z., Gao, Y. G., and Xia, Y. (2018). Multifunctional roles of plant cuticle during plant-pathogen interactions. Front. Plant Sci. 9:1088. doi: 10. 3389/fpls.2018.01088

Conflict of Interest Statement: The authors declare that the research was conducted in the absence of any commercial or financial relationships that could be construed as a potential conflict of interest.

Copyright (C) 2019 Trivedi, Nguyen, Hykkerud, Häggman, Martinussen, Jaakola and Karppinen. This is an open-access article distributed under the terms of the Creative Commons Attribution License (CC BY). The use, distribution or reproduction in other forums is permitted, provided the original author(s) and the copyright owner(s) are credited and that the original publication in this journal is cited, in accordance with accepted academic practice. No use, distribution or reproduction is permitted which does not comply with these terms. 